Article

\title{
Rambutan-like CoP@Mo-Co-O hollow microspheres for efficient hydrogen evolution reaction in alkaline solution
}

\author{
Wen Zhou, Mingmei Wu \#, Gaoren Li * \\ School of Chemistry, Sun Yat-sen University, Guangzhou 510275, Guangdong, China
}

\section{A R T I C L E I N F}

\section{Article history:}

Received 14 September 2019

Accepted 18 October 2019

Published 5 April 2020

\section{Keywords:}

CoP@Mo-Co-O

Rambutan-like hollow microspheres

Interfacial effect

Hydrogen evolution reaction

\begin{abstract}
A B S T R A C T
Water electrolysis has attracted a lot of attention in recent years for hydrogen production. CoP has been widely investigated as a traditional electrocatalyst for hydrogen evolution reaction (HER). However, the strong bond strength of $\mathrm{P}-\mathrm{H}$ bond and weak chemical stability are still the key problems in affecting catalytic performance of CoP. In this work, we synthesized rambutan-like CoP@Mo-Co-O hollow microspheres as HER electrocatalyst, solving the two problems of CoP as electrocatalyst. Benefiting from the unique three-dimensional space structure and interface effect between CoP and Mo-Co-0, the synthesized CoP@Mo-Co-O shows a small overpotential of $62 \mathrm{mV}$ at the current density of $10 \mathrm{~mA} \mathrm{~cm}^{-2}$ for HER, which is much lower than the corresponding overpotential of pure CoP microspheres (117 mV). Rambutan-like CoP@Mo-Co-O hollow microspheres also show robust long-term stability and excellent cycling stability. This work provides a new method for the design and improvement of non-precious HER electrocatalysts.
\end{abstract}

(C) 2020, Dalian Institute of Chemical Physics, Chinese Academy of Sciences. Published by Elsevier B.V. All rights reserved.

\section{Introduction}

Hydrogen is regarded as the most promising energy due to its high energy density, zero emission and renewable characteristics [1-4]. Electrolysis of water is an effective way to produce high purity hydrogen among various hydrogen production methods [5,6]. The half reaction of water electrolysis at the cathode, named the hydrogen evolution reaction (HER), requires active catalysts to reduce the decomposition overpotential, promote its slow kinetic process, and improve the water splitting efficiency $[7,8]$. Currently, high-performance electro-catalysts for HER are mainly precious metal materials, such as platinum $[9,10]$. However, the high cost greatly hinders the application of precious metal materials in electrocatalytic water splitting.

As we all know, HER is more likely to occur at high proton concentrations, so it is more challenging to investigate electro- catalysts for HER under alkaline conditions than under acid conditions [11,12]. Moreover, acidic electrolyte is more corrosive to equipment in industrial applications. Therefore, the research on catalysts for HER applied in alkaline solution is more promising. Transition metal phosphides (TMP) have been widely studied as excellent electrocatalysts for HER with low initial overpotential and small Tafel slope, especially CoP [13-15]. However, the stability of TMP as catalysts for HER is weak in both acid or alkaline solution [16]. Introduction of molybdenum element is a feasible method to improve the stability of transition metal compounds as electrocatalyst [17]. Molybdenum is often in a high valence state (hexavalent). And high-valence transition metal cations are conducive to promoting the activation of water molecules, making it easier for water molecules to dissociate into hydrogen ions and hydroxide ions [17].

Electrochemical catalytic efficiency is also affected by the

\footnotetext{
* Corresponding author. Tel: +86-20-84110085; E-mail: ligaoren@mail.sysu.edu.cn

\# Corresponding author. E-mail: ceswmm@mail.sysu.edu.cn

DOI: 10.1016/S1872-2067(20)63530-6 | http://www.sciencedirect.com/science/journal/18722067 | Chin. J. Catal., Vol. 41, No. 4, April 2020
} 
morphology and conductivity of materials. Large specific surface area of a catalyst can expose more active sites and facilitate mass transfer between the catalyst and solution. One-dimensional linear array structure and hollow structure are often adopted for electrochemical catalyst materials because such structures have large specific surface area [18-20]. As reported, metal phosphides have good electrical conductivity, which may be caused by the existence of metal-metal bonds in the phosphides [21]. Therefore, to synthesize transition metal phosphide with special morphologies (such as hollow structure, array structure, etc.) can meet the two requirements in large surface area and good electrical conductivity of catalysts for HER.

Utilizing interfacial effect is a good way to improve activity of catalysts [22,23]. HER catalysts often have problems of too strong or too weak proton adsorption energy and poor stability. These problems can be solved by interface effect. The electron density of catalyst can be adjusted to achieve an ideal hydrogen adsorption free energy through interfacial effect, and proper interface effect can also stabilize the performance of catalyst [24].

In this work, rambutan-like Mo-Co-O hollow microspheres were firstly synthesized by a hydrothermal method as the precursor. The hollow rambutan-like structure was realized by the mechanism of Ostwald Ripening under the guidance of molybdate ions [25]. The precursor was treated with sodium hypophosphite in $\mathrm{N}_{2}$ atmosphere to obtain the target composite of CoP and Mo-Co-O (CoP@Mo-Co-O). CoP@Mo-Co-O shows excellent electrochemical HER catalytic performance in alkaline electrolyte. The corresponding hydrogen evolution overpotential is only $62 \mathrm{mV}$ at the current density of $10 \mathrm{~mA} \mathrm{~cm}-2$. Owing to the interfacial effect between $\mathrm{CoP}$ and Mo-Co-O, the catalytic activity and stability of the rambutan-like CoP@Mo-Co-O hollow spheres are greatly improved compared with that of single CoP.

\section{Experimental}

\subsection{Synthesis of rambutan-like Mo-Co-O hollow microspheres as precursor}

All chemical reagents used in this work were analytical grade. $0.6 \mathrm{~g} \mathrm{Co}\left(\mathrm{NO}_{3}\right)_{2} \cdot 6 \mathrm{H}_{2} \mathrm{O}, 0.05 \mathrm{~g} \mathrm{Na}_{2} \mathrm{MoO}_{4} \cdot 2 \mathrm{H}_{2} \mathrm{O}, 0.6 \mathrm{~g}$ urea, and $0.18 \mathrm{~g} \mathrm{NH}_{4} \mathrm{~F}$ were dissolved in $35 \mathrm{~mL}$ deionized water. The solution was then transferred to a $50 \mathrm{~mL}$ of Teflon stainless-lined steel autoclave and heated at $120^{\circ} \mathrm{C}$ for $6 \mathrm{~h}$. After cooling down to room temperature, the powder was obtained by centrifugation, then washed with deionized water and ethanol several times, and dried in an oven at $60^{\circ} \mathrm{C}$ for $6 \mathrm{~h}$. We got a pink powder finally.

\subsection{Synthesis of rambutan-like CoP@Mo-Co-O hollow microspheres}

All the rambutan-like Mo-Co-O hollow microspheres obtained above were transferred to a quartz boat and put into the middle of the tube furnace. Then we placed $1 \mathrm{~g} \mathrm{NaH} 2 \mathrm{PO}_{2} \cdot \mathrm{H}_{2} \mathrm{O}$ in another quartz boat and put the boat in the upper side of the tube furnace. The temperature rose to $300^{\circ} \mathrm{C}$ at a heating rate of $2{ }^{\circ} \mathrm{C} / \mathrm{s}$. The temperature was kept at $300{ }^{\circ} \mathrm{C}$ for $2 \mathrm{~h}$, and then decreased to room temperature naturally. The powder was washed with deionized water, dilute hydrochloric acid, and anhydrous ethanol several times and then dried at room temperature.

\subsection{Synthesis of CoP microspheres}

The synthesis method of pure CoP microspheres was almost the same as that of CoP@Mo-Co-O hollow microspheres above, excepting that $\mathrm{Na}_{2} \mathrm{MoO}_{4} \cdot 2 \mathrm{H}_{2} \mathrm{O}$ was not added in the initial precursor. The pure CoP microspheres were synthesized for the comparison with rambutan-like CoP@Mo-Co-O hollow microspheres.

\subsection{Characterizations}

Scanning electron microscopy (SEM) measurement was carried out on a FEI Quanta-400 SEM. Transmission electron microscopy (TEM) images were measured by a FEI TECNAI F30 TEM. The compositions of the samples were characterized by X-ray diffractometry (XRD, D-MAX 2200 VPC). The valence distribution of elements was characterized by X-ray photoelectron spectroscopy (XPS, ESCALAB MKII).

\subsection{Electrochemical measurements}

The as-prepared CoP@Mo-Co-O and CoP were deposited on a glassy carbon electrode via a drop-casting approach, and the catalyst loading was about $0.50 \mathrm{mg} \mathrm{cm}^{-2}$. The electrochemical experiments were performed in a three-electrode system with a $\mathrm{CHI} 760 \mathrm{E}$ electrochemical workstation in $1 \mathrm{M} \mathrm{KOH}$ at room temperature. The glassy carbon with active catalyst materials was used as work electrode. The counter electrode and the reference electrode were a graphite rod and a $\mathrm{HgO}$ electrode, respectively. Linear sweep voltammetry (LSV), electrochemical impedance spectroscopy (EIS), chronopotentiometry and cyclic voltammetry $(\mathrm{CV})$ were performed to characterize the electrochemical property of samples. All the potentials in this work were respect to reversible hydrogen electrode (RHE) with compensation for the ohmic potential drop losses.

\section{Results and discussion}

SEM was used to characterize the morphology of the synthesized rambutan-like CoP@Mo-Co-0 hollow microspheres and pure CoP microspheres. The SEM images are shown in Fig. 1. Figures $1 \mathrm{a}$ and $1 \mathrm{~b}$ are SEM images of CoP microspheres at different resolutions. It can be seen that CoP microspheres consist of CoP nanowires. Figures $1 \mathrm{c}$ and $1 \mathrm{~d}$ are SEM images of CoP@Mo-Co-O at different resolutions. The morphology of CoP@Mo-Co-O turns into a very interesting structure: the inside is hollow, and the outside wall is made of nanowires. The special morphology is like the fruit rambutan. The broken part in Fig. 1c shows obviously the hollow structure of 


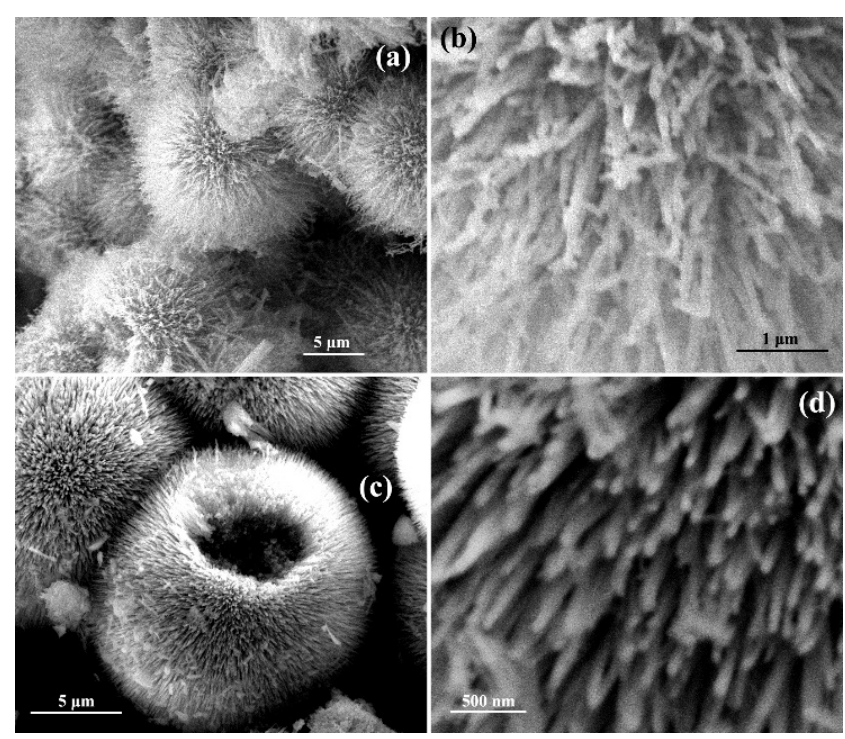

Fig. 1. (a, b) SEM images of CoP microspheres at different resolutions; (c, d) SEM images of rambutan-like CoP@Mo-Co-O hollow microspheres at different resolutions.

CoP@Mo-Co-O. This indicates that Ostwald Ripening reaction takes place under the guidance of molybdate ions in the process of hydrothermal reaction to realize the hollow structure by one step. The hollow structure of CoP@Mo-Co-O can be directly verified by subsequent TEM characterization. The average di- ameter of CoP@Mo-Co-O is about $12 \mu \mathrm{m}$. The mechanism of Ostwald Ripening is that the interior part of sphere is more active, so the interior part is dissolved firstly under hydrothermal conditions, and grows again on the outside. Such a dissolution-regeneration process lasts for a period of time to form a hollow structure [25]. The one-step synthetic method by Ostwald Ripening mechanism to form the hollow structure does not need the sacrifice of templates like the tradition synthetic method, which simplifies the complicated steps of synthesis. In addition, it is often difficult to completely dissolve the template material in the traditional template method when dissolving the template, and the residual template material will affect the activity of catalyst. However, Ostwald Ripening principle without the use of templates has no such concern. As can be seen from Fig. 1, the nanowires of CoP@Mo-Co-O are shorter than those of CoP, but more orderly, which is more beneficial to the mass transfer between the active sites of catalyst and electrolyte, and improves the catalytic efficiency.

The compositions of materials synthesized in this work were characterized by XRD. The valence states of elements and the electron flow between elements were characterized by XPS. XRD and XPS characterization results are shown in Fig. 2. Figure 2a is Co $2 p$ spectra of CoP and CoP@Mo-Co-O. The peak at $778.6 \mathrm{eV}$ in Co $2 p$ spectra of both CoP and CoP@Mo-Co-O is corresponding to metal $\mathrm{Co}\left(\mathrm{Co}^{0}\right)$. The results indicate that some cobalt ions are reduced to $\mathrm{Co}^{0}$ due to the reduction of $\mathrm{H}_{3} \mathrm{P}$ gas produced by the decomposition of $\mathrm{NaH}_{2} \mathrm{PO}_{2}$. The metal-metal
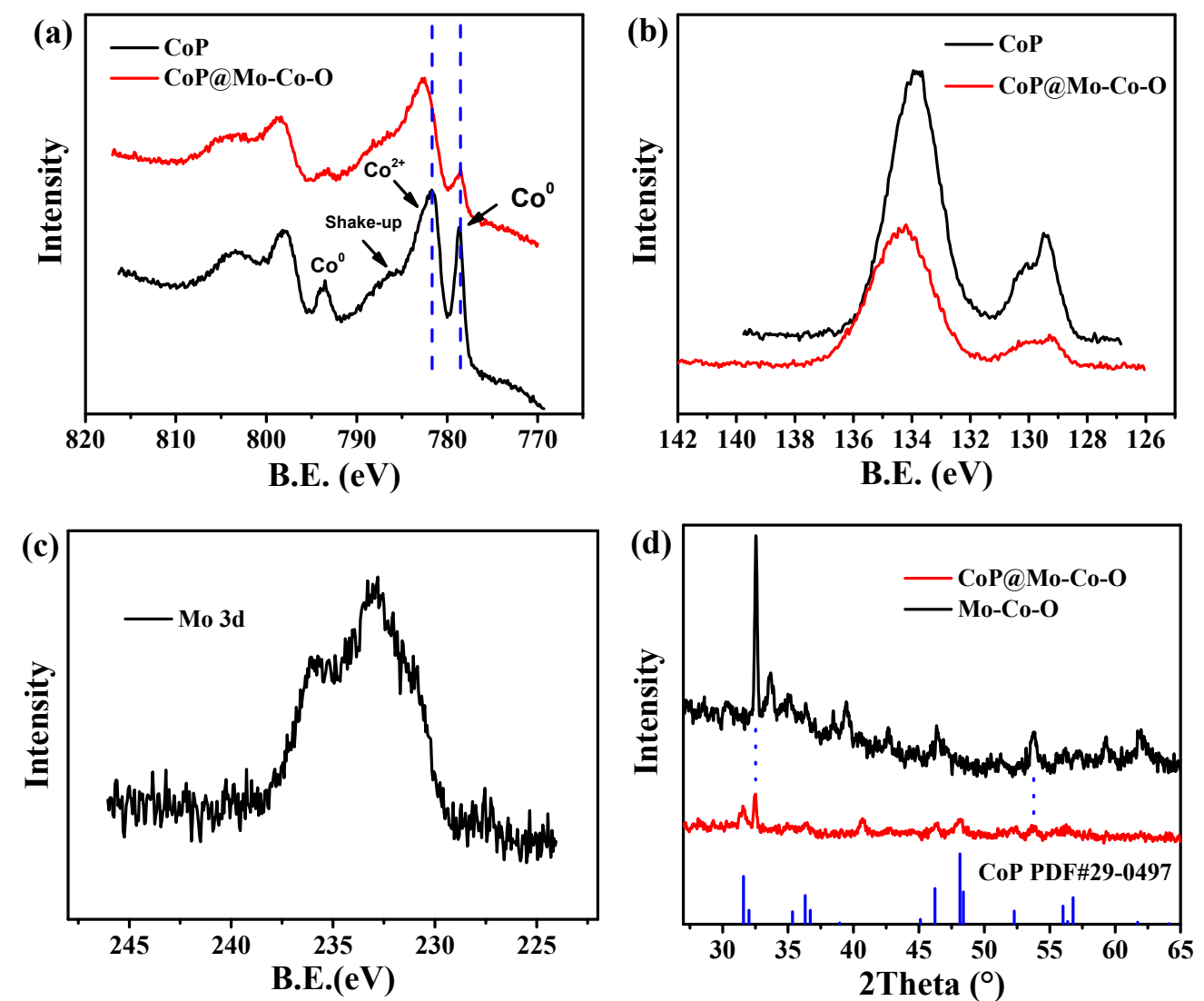

Fig. 2. (a) Co $2 p$ XPS spectra and (b) P $2 p$ XPS spectra of CoP@Mo-Co-O and CoP; (c) Mo 3d XPS spectrum of CoP@Mo-Co-0; (d) XRD patterns of CoP@Mo-Co-O and Mo-Co-O. 
bond (Co-Co bond) existed in $\mathrm{CoP}$ is the reason for the good electrical conductivity of CoP-based materials. The peak assigned to $\mathrm{Co}^{2+}$ of pure $\mathrm{CoP}$ is located at $781.7 \mathrm{eV}$, while the peak assigned to $\mathrm{Co}^{2+}$ of CoP@Mo-Co-O is located at $782.6 \mathrm{eV}$. The bind energy of $\mathrm{Co}^{2+}$ in CoP@Mo-Co-O is about $0.9 \mathrm{eV}$ higher than that in CoP. The result reveals that with the introduction of Mo element, the electrons flow to high valence Mo ions from $\mathrm{Co}^{2+}$, thus making the electron binding energy of $\mathrm{Co}^{2+}$ increased.

According to the reported literature [26], the HER mechanism of CoP catalyst is that the phosphorus sites act as proton-acceptor centers and the cobalt sites act as the hydride-acceptor. The CoP catalyst is easy to adsorb proton to form cobalt hydride species for next hydrogen evolution, but the adsorbed proton is comparatively difficult for desorption to form Hydrogen molecules released, which influences the catalytic performance of CoP. As seen from the above XPS results, the bind energy of $\mathrm{Co}^{2+}$ in CoP@Mo-Co-O is higher than that in pure CoP. It means that the electron density of cobalt sites in CoP@Mo-Co-O is lower than in CoP. The decrease in the electron density of cobalt sites can facilitate the desorption of proton from cobalt hydride species, which solves the problem of proton-desorption for CoP catalyst. Therefore, the interfacial effect between CoP and Mo-Co-O can promote the proton adsorption energy of catalyst to reach a more ideal value for HER.

The P $2 p$ XPS spectra of CoP and CoP@Mo-Co-O are shown in Fig. 2b. The peak assigned to phosphorous anion in the CoP is located in the range of $127-131 \mathrm{eV}$. The peak at $131-139 \mathrm{eV}$ corresponds to phosphorus oxide. It can be seen that the electron binding energy of phosphorous anion in CoP@Mo-Co-O is slightly offset to the lower value compared to that of phosphorous anion in CoP, indicating that there are electrons flowing from the introduced molybdenum element to phosphorus anion. Figure 2c shows the Mo 3d XPS spectrum of CoP@Mo-Co-O. The valence of Mo element presents a multivalent state of mainly $\mathrm{Mo}^{4+}$ and $\mathrm{Mo}^{6+}$. Molybdenum ions at high-valence state have stronger electron accepting ability and more powerful electron effect with CoP, which plays an important role in regulating the electron density of $\mathrm{CoP}$ and activating water molecules.

The XRD patterns of CoP@Mo-Co-O and Mo-Co-O precursor are shown in Fig. 2d. The diffraction peaks of CoP@Mo-Co-O at $31.6^{\circ}, 36.4^{\circ}, 46.3^{\circ}$, and $48.1^{\circ}$ correspond to the (011), (111), (112), and (211) planes of CoP (JCPDS card no. 29-0497), respectively. The diffraction peaks at $32.5^{\circ}$ and $53.8^{\circ}$ of CoP@Mo-Co-O are consistent with the diffraction peaks of Mo-Co-O precursor. The XRD result conforms the composite of CoP@Mo-Co-O. It is shown that the method of phosphating using $\mathrm{NaH}_{2} \mathrm{PO}_{2}$ in $\mathrm{N}_{2}$ gas at $300{ }^{\circ} \mathrm{C}$ is only a kind of surface phosphating. The surface of the precursor was turned to CoP after the phosphate treatment, and then we got the composite material of CoP@Mo-Co-O.

Figure 3a is the TEM image of rambutan-like CoP@Mo-Co-O hollow microspheres. We pick a microsphere with a relatively small size in the sample because the diameter is more suitable for TEM characterization. TEM image can further confirm the hollow structure of CoP@Mo-Co-O. Due to the influence of ul-

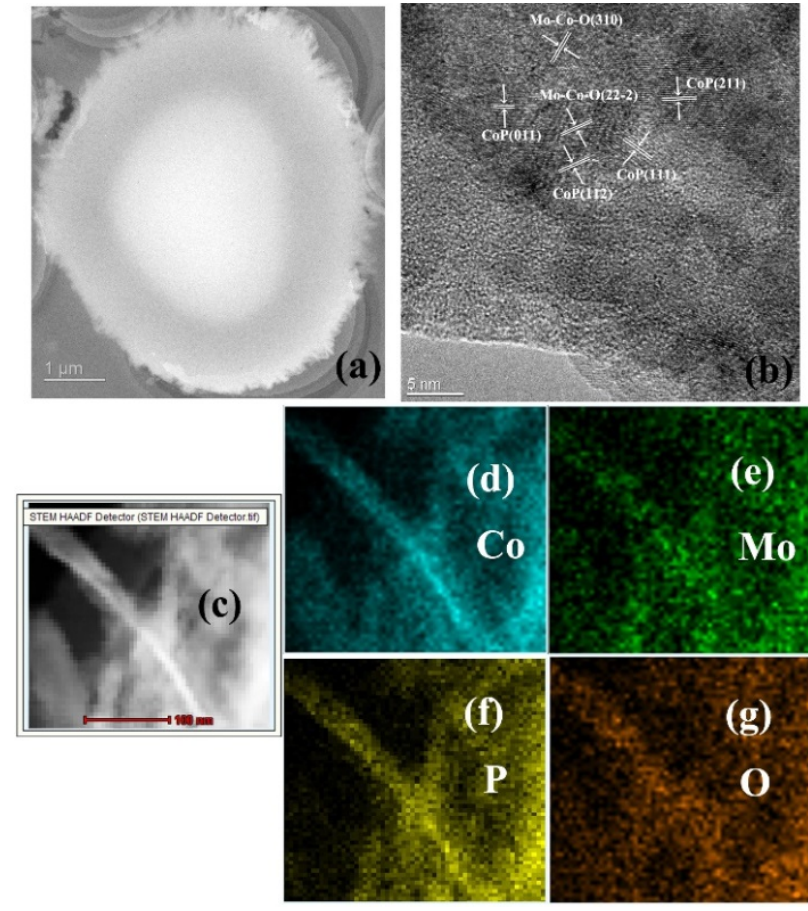

Fig. 3. (a) TEM image of CoP@Mo-Co-O; (b) HRTEM image of CoP@Mo-Co-O; (c-g) EDS maps of CoP@Mo-Co-O.

trasonic dispersive of sample for TEM characterization, some nanowire arrays on the outer wall of CoP@Mo-Co-O have fallen off, but the nanowire array structure of the outer wall could still be seen in Fig. 3a. High-resolution transmission electron microscopy (HRTEM) of CoP@Mo-Co-O is shown in Fig. 3b. The crystal lattices assigned to CoP and Mo-Co-O can be observed in Fig. 3b. The close positional relation of crystal lattices belonging to $\mathrm{CoP}$ and Mo-Co-O facilitate the interaction between CoP and Mo-Co-O.

Figures $3 \mathrm{c}-3 \mathrm{~g}$ shows the element distribution map of CoP@Mo-Co-O, and the scanning area is a nanowire on the wall of rambutan-like CoP@Mo-Co-O hollow microspheres. As we can see from Fig. 3c-3g, the element distributions of Co, Mo, P, and $\mathrm{O}$ are very uniform. However, the distribution diagrams of Co and $\mathrm{P}$ are much clearer than that of Mo and $\mathrm{O}$, indicating that the content of $\mathrm{Co}$ and $\mathrm{P}$ on the surface is much higher than that of Mo and 0 . The amount of Mo in the initial reaction is only one-tenth of cobalt, so the content of Mo is much lower than Co. The surface of sample contains a lot of $P$ element and a small amount of 0 element, which shows that the catalyst has been phosphated adequately on the surface.

The electrochemical performance of CoP@Mo-Co-O and CoP was characterized by using a three-electrode system in $1 \mathrm{M}$ KOH solution. The results of electrochemical characterization are shown in Fig. 4. The LSV curves have been corrected with iR drop. As shown in Fig. 4a, when the current density is $10 \mathrm{~mA}$ $\mathrm{cm}^{-2}$, the corresponding overpotential of CoP is $117 \mathrm{mV}$. The overpotential of CoP@Mo-Co-O is only $62 \mathrm{mV}$ at current density of $10 \mathrm{~mA} \mathrm{~cm}^{-2}$, which is $55 \mathrm{mV}$ lower than that of CoP. Figure $4 \mathrm{~b}$ shows the Tafel curves of CoP@Mo-Co-O and CoP. The Tafel

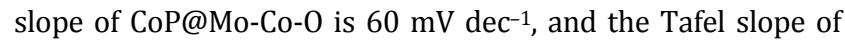



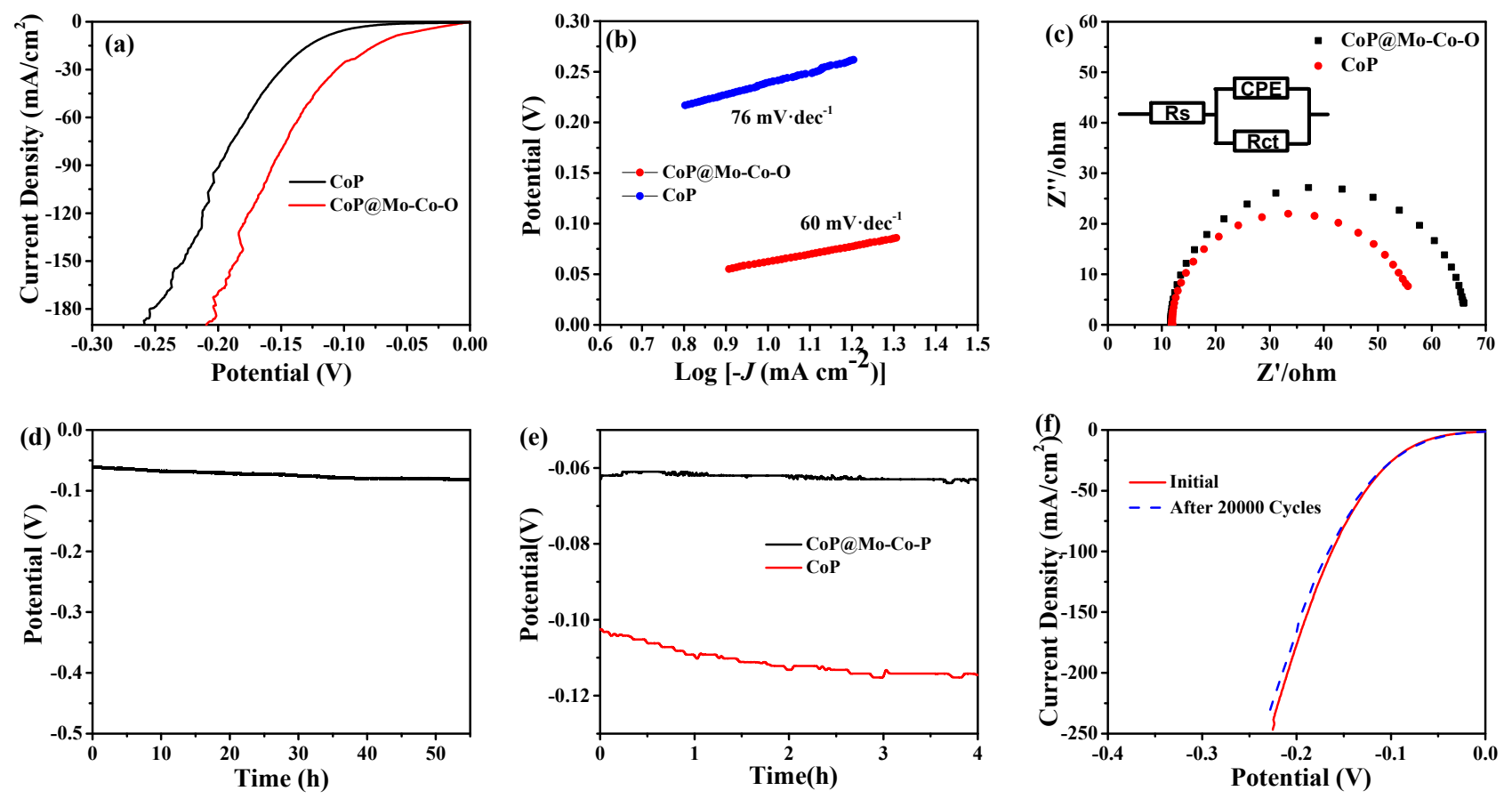

Fig. 4. (a) LSVs of CoP@Mo-Co-O and CoP in $1 \mathrm{M} \mathrm{KOH}$ at 5 mV s${ }^{-1}$; (b) Tafel plots and (c) A.C. impedance plots of CoP@Mo-Co-O and CoP; (d) Chrono-potentiometry curves of CoP@Mo-Co-0 with a current density of $10 \mathrm{~mA} \mathrm{~cm}{ }^{-2}$ for $55 \mathrm{~h}$; (e) Chrono-potentiometry curves of CoP@Mo-Co-0 and CoP in the first $4 \mathrm{~h}$; (f) Cycle stability measurement of CoP@Mo-Co-O via a CV scanning for 2000 cycles in 1 M KOH solution.

$\mathrm{CoP}$ is $76 \mathrm{mV} \mathrm{dec}{ }^{-1}$. Therefore, the hydrogen evolution mechanisms of CoP@Mo-Co-O and CoP are both Volmer-Heyrovsky mechanism, and the Heyrovsky step is the rate-determining step [27]. The Tafel slope of CoP@Mo-Co-O is lower than that of CoP, showing that the HER catalytic activity of CoP@Mo-Co-O is higher than CoP.

The A.C. impedance diagram of CoP@Mo-Co-O and CoP is shown in Fig. 4c. The charge transfer resistance $\left(R_{\mathrm{ct}}\right)$ of CoP is about $55 \Omega$, and the $\mathrm{R}_{\mathrm{ct}}$ of CoP@Mo-Co- $\mathrm{O}$ is about $45 \Omega$, which is about $10 \Omega$ lower than that of CoP. In general, the combination of CoP and Mo-Co-O will decrease the conductivity of CoP due to the poor conductivity of transition metal oxides. However, owing to the unique rambutan-like hollow structure of CoP@Mo-Co-O, the catalyst contacts with the electrolyte solution more fully. Therefore, the conductivity of rambutan-like CoP@Mo-Co-O hollow microspheres is even better than pure CoP microspheres. The electrochemical active surface areas (ECSA) of CoP@Mo-Co-O and CoP are evaluated by their electrochemical double layer capacitances $\left(C_{\mathrm{dl}}\right)$, which can be calculated from CV curves shown in Fig. S2. CoP@Mo-Co-O shows a $C_{\mathrm{dl}}$ value of of $36.53 \mathrm{mF} \mathrm{cm}-2$, which is about 4 times higher than that of CoP (8.91 $\left.\mathrm{mF} \mathrm{cm}^{-2}\right)$, suggesting that the ECSA of CoP@Mo-Co-O is much larger than that of CoP.

The stability for HER in $1 \mathrm{M} \mathrm{KOH}$ solution was measured by the method of chronopotentiometry at the current density of $10 \mathrm{~mA} \mathrm{~cm}^{-2}$. Figure $4 \mathrm{~d}$ shows the chronopotentiometry curve of CoP@Mo-Co-O for $55 \mathrm{~h}$. After the stability test for $55 \mathrm{~h}$, the overpotential of the CoP@Mo-Co-O at the current density of 10 $\mathrm{mA} \mathrm{cm}-2$ is only increased by about $17 \mathrm{mV}$. The catalytic activity of catalyst is always decreased rapidly at early time during stability test, and then keeps in a relative stable value. The chronopotentiometry curves of CoP@Mo-Co-O and CoP in the first $4 \mathrm{~h}$ are shown in Fig. 4e. We can find that the stability of CoP decreases a lot in the first $4 \mathrm{~h}$, while stability decay of CoP@Mo-Co-O is almost negligible in the first $4 \mathrm{~h}$. This indicates that the combination with Mo-Co-O can greatly improve the stability of $\mathrm{CoP}$, and overcome the problem of instability for CoP-based material as HER catalyst. The cycle stability test of CoP@Mo-Co-O is shown in Fig. 4f. After 2000 cycles in $1 \mathrm{M} \mathrm{KOH}$ solution, the polarization curve of CoP@Mo-Co-O has hardly changed compared to that of the first cycle, showing excellent cycle stability. The XPS and SEM characterizations of CoP@Mo-Co-O after the long-time reaction are provided in Fig. S3, confirming the stability of CoP@Mo-Co-O.

\section{Conclusions}

In this work, we synthesized rambutan-like Mo-Co-O hollow microspheres as precursor firstly. The hollow structure is formed by using Ostwald Ostwald Ripening principle, which does not need to sacrifice template like the traditional method. The rambutan-like CoP@Mo-Co-O hollow microspheres were obtained by treating Mo-Co-O precursor with $\mathrm{NaH}_{2} \mathrm{PO}_{2} \cdot \mathrm{H}_{2} \mathrm{O}$ at $300{ }^{\circ} \mathrm{C}$. The prepared CoP@Mo-Co-O shows a good catalytic performance for HER under alkaline conditions. The corresponding overpotential at the current density of $10 \mathrm{~mA} \mathrm{~cm}^{-2}$ is only $62 \mathrm{mV}$ and the Tafel slope is as low as $60 \mathrm{mV} \mathrm{dec}^{-1}$. The overpotential at $10 \mathrm{~mA} \mathrm{~cm}-2$ is only increased by about $17 \mathrm{mV}$ after stability test for $55 \mathrm{~h}$ in $1 \mathrm{M} \mathrm{KOH}$ solution, showing a very strong long-term stability in alkaline solution. And 
CoP@Mo-Co-O also shows excellent cycle stability. The HER catalytic performance of CoP@Mo-Co-O is significantly improved compared with that of pure $\mathrm{CoP}$, and close to the catalytic activity of precious metal Pt. The advantages and innovations of CoP@Mo-Co-O as an alkaline HER electrocatalyst can be summarized as follows. (i) Facile and convenient synthesis method. The hollow structure of CoP@Mo-Co-O is realized by one-step hydrothermal reaction guided by molybdate ion using Ostwald Ripening principle. The facile synthesis method need not the complex steps of hollow structure synthesis by a traditional template method, and the bad influence of incomplete template dissolution on the catalytic properties of catalysts is avoided. (ii) Unique three-dimensional space structure. The morphology of CoP@Mo-Co-O is rambutan-like hollow microspheres. The internal of CoP@Mo-Co-O is hollow, and the outer wall is surrounded by nanowire arrays, similar to the appearance of the fruit rambutan. This unique three-dimensional structure has a large specific surface area, which can expose more active sites, contact with electrolyte solution more sufficiently, and reduce mass transfer impedance. (iii) The helpful interface effect for HER catalysis. In the catalyst CoP@Mo-Co-O, the interface effect between Mo-Co-O and CoP can reduce electron density of CoP layer, facilitating the adsorbed protons to form hydrogen gas evolved. So, the whole catalytic performance for HER in alkaline solution of CoP@Mo-Co-O has a great improvement compared to that of pure CoP. At the same time, Mo-Co-O layer also plays an important role in the activation of water molecules and the improvement of electrochemical stability of catalyst. To summarize the above all, the rambutan-like CoP@Mo-Co-O hollow microspheres we synthesized have superior catalytic activity and high stability as a kind of non-noble metal catalyst for HER in alkaline solution, and have great application prospects in the field of alkaline electrocatalytic water splitting.

\section{References}

[1] J. Xing, F. Lin, L. Huang, Y. Si, Y. Wang, L. Jiao, Chin. J. Catal., 2019, $40,1352-1359$
[2] H. Zhang, B. Yang, X. Wu, Z. Li, L. Lei, X. Zhang, ACS Appl. Mater. Interfaces, 2015, 7, 1772-1779.

[3] X. Gao, H. Zhang, Q. Li, X. Yu, Z. Hong, X. Zhang, C. L, Z. L, Angew. Chem., 2016, 128, 6398-6402.

[4] P. Wang, K. Jiang, G. Wang, J. Yao, X. Huang, Angew. Chem. Int. Ed., 2016, 55, 12859-12863.

[5] S. Hao, L. Chen, C. Yu, B. Yang, Z. Li, Y. Hou, L. Lei, X. Zhang, ACS Energy Lett., 2019, 4, 952-959.

[6] P. F. Cheng, T. Feng, Z. W. Liu, D. Y. Wu, J. Yang, Chin. J. Catal., 2019, $40,1147-1152$.

[7] Y. Zheng, Y. Jiao, A. Vasileff, S. Z. Qiao, Angew. Chem. Int. Ed., 2018, $57,7568-7579$.

[8] Q. Jin, B. Ren, D. Li, H. Cui, C. Wang, Nano Energy, 2018, 49, 14-22.

[9] H. Zhang, P. An, W. Zhou, B. Y. Guan, P. Zhang, J. Dong, X. W. Lou, Sci. Adv., 2018, 4, eaao6657.

[10] H. C. Kwon, M. Kim, J. P. Grote, S. J. Cho, M. W. Chung, H. K. Kim, D. H. Won, A. R. Zeradjanin, K. J. J. Mayrhofer, M. Choi, H. Kim, C. H. Choi, J. Am. Chem. Soc., 2018, 140, 16198-16205.

[11] Y. Yan, R. W. Crisp, J. Gu, B. D. Chernomordik, G. F. Pach, A. R. Marshall, J. A. Turner, M. C. Beard, Nat. Energy, 2017, 2, 17052.

[12] D. Escalera-López, Z. Lou, N. V. Rees, Adv. Energy Mater., 2019, 9, 1802614.

[13] C. Wu, Y. Yang, D. Dong, Y. Zhang, J. Li, Small, 2017, 13, 1602873.

[14] J. X. Feng, S. Y. Tong, Y. X. Tong, G. R. Li, J. Am. Chem. Soc., 2018, 140, 5118-5126.

[15] M. Q. Wang, C. Ye, H. Liu, M. Xu, S. J. Bao, Angew. Chem. Int. Ed., 2018, 57, 1963-1967.

[16] Y. Zhang, L. Gao, E. J. M. Hensen, J. P. Hofmann, ACS Energy Lett., 2018, 3, 1360-1365.

[17] J. Staszak-Jirkovský, C. D. Malliakas, P. P. Lopes, N. Danilovic, S. S. Kota, K. C. Chang, B. Genorio, D. Strmcnik, V. R. Stamenkovic, M. G. Kanatzidis, N. M. Markovic, Nat. Mater., 2016, 15, 197-203.

[18] Z. Wang, X. Ren, Y. Luo, L. Wang, G. Cui, F. Xie, H. Wang, Y. Xie, X. Sun, Nanoscale, 2018, 10, 12302-12307.

[19] Z. F. Huang, J. Song, K. Li, M. Tahir, Y. T. Wang, L. Pan, L. Wang, X. Zhang, J. J. Zou, J. Am. Chem. Soc., 2016, 138, 1359-1365.

[20] Z. Z. Liu, X. Shang, B. Dong, Y. M. Chai, J. Catal., 2018, 361, 204-213.

[21] S. H. Ye, J. X. Feng, G. R. Li, ACS Catal., 2016, 6, 7962-7969.

[22] B. Zhang, J. Liu, J. Wang, Y. Ruan, X. Ji, K. Xu, C. Chen, H. Wan, L. Miao, J. Jiang, Nano Energy, 2017, 37, 74-80.

[23] P. Wang, Y. Sheng, F. Wang, H. Yu, Appl. Catal. B, 2018, 220, 561-569.

\section{Graphical Abstract}

Chin. J. Catal., 2020, 41: 691-697 doi: 10.1016/S1872-2067(20)63530-6

Rambutan-like CoP@Mo-Co-O hollow microspheres for efficient hydrogen evolution reaction in alkaline solution

Wen Zhou, Mingmei Wu *, Gaoren Li *

Sun Yat-sen University

We synthesized CoP@Mo-Co-0 with rambutan-like hollow structure by Ostwald-ripening principle. Owing to its special three-dimensional hollow structure and interface effect, CoP@Mo-Co-O showed an excellent activity and stability for hydrogen evolution reaction in alkaline solution.

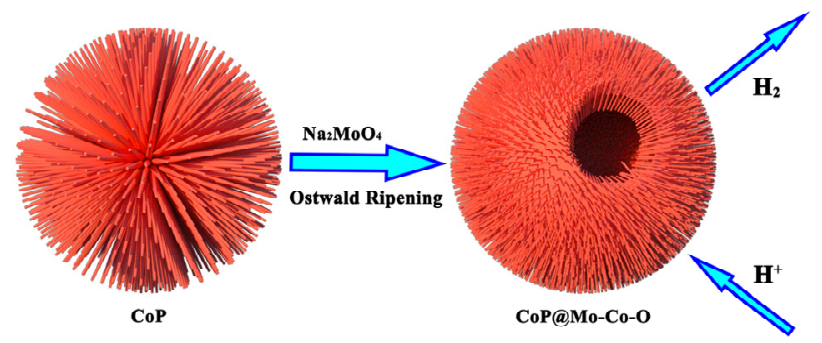


[24] M. Tariq, W. Q. Zaman, W. Sun, Z. Zhou, Y. Wu, L. Cao, Y. Yang, ACS Sustain. Chem. Eng., 2018, 6, 4854-4862.

[25] L. Zhou, W. Wang, H. Xu, S. Sun, Cryst. Growth Des., 2008, 8, 3595-3601.
[26] Q. Liu, J. Tian, W. Cui, P. Jiang, N. Cheng, A. M. Asiri, X. Sun, Angew. Chem. Int. Ed., 2014, 53, 6710-6714.

[27] M. Xu, L. Han, Y. Han, Y. Yu, J. Zhai, S. Dong, J. Mater. Chem. A, 2015, 3, 21471-21477.

\title{
红毛丹状磷化钴@钼钴氧空心微米小球用于碱性电催化析氢
}

\author{
周文, 吴明娒”, 李高仁 \\ 中山大学化学学院, 广东广州 510275
}

摘要: 氢气因其能量密度高、零排放和可再生的特点被广泛认为是最有前景的能源. 电解水是一种产生高纯氢气的有效途 径. 目前, 高性能的促进水电解的催化剂主要是贵金属材料, 例如贵金属铂. 然而, 高成本大大阻碍了贵金属材料在电催化 水分解中的广泛应用. 因此, 我们致力于研究具有高活性的非贵金属催化剂.

因为电催化水分解析氢反应更容易发生在质子浓度高的条件下, 所以研究碱性条件下催化析氢比研究酸性条件下催 化析氢更具挑战性. 在工业应用中, 酸性电解质溶液对仪器设备的腐蚀性比碱性溶液更大, 因此研究应用在碱性溶液中的 析氢催化剂更有发展前景. 过渡金属磷化物被广泛地研究作为高性能析氢电催化剂, 然而过渡金属磷化物作为析氢催化 剂的稳定性通常不是很好. 我们通过锄元素的引入, 提高过渡金属磷化物作为析氢催化剂的稳定性. 电化学催化效率同样 受到材料形貌和导电性的影响. 大的比表面积有利于暴露更多的活性位点, 使活性位点与电解质溶液的接触更加充分, 有 利于催化剂和溶液之间的传质. 据报道, 金属磷化物具有良好的导电性是由于磷化物中存在金属-金属键. 所以合成具有 大比表面积形貌的过渡金属磷化物材料能够满足析氢电催化剂对比表面积和导电性的两个需求.

界面效应是调节催化剂性能的一个有效方法. 析氢催化剂常常存在吸附质子能力过强或过弱、稳定性不好等问题. 这 些问题可以通过界面效应来解决. 本文通过形成磷化估和钿钴氧的界面来调节改善磷化钴表面原来的电子密度, 以达到 理想的氢吸附自由能; 同时此界面效应还能起到稳定催化剂性能的作用.

本文首先采用水热法合成了红毛丹状钿钴氧空心微米小球前驱体. 在钼酸根离子的引导下, 利用奥斯特瓦尔德熟化 原理一步实现了红毛丹状空心结构. 前驱体再以次亚磷酸钠为磷源进行气相磷化, 得到产物红毛丹状磷化钴@钼钴氧空心 微米小球. 通过扫描电镜和透射电镜对其红毛丹状空心结构进行了表征. 利用X射线衍射和X射线光电子能谱等手段表征 了材料的物相组成和价态分布. 电化学测试均使用电化学工作站完成. 该材料在碱性电解质溶液中展现了极好的电化学 催化析氢性能, 在电流密度为 $10 \mathrm{~mA} \mathrm{~cm}$ 时对应的析氢过电位仅为 $62 \mathrm{mV}$. 在 $1 \mathrm{M} \mathrm{KOH}$ 溶液中 $10 \mathrm{~mA} \mathrm{~cm}$ 电流密度下测试 $55 \mathrm{~h}$, 过电位仅增大约 $17 \mathrm{mV}$, 显示了非常强的碱性析氢稳定性. 得益于磷化钴和钼钴氧之间的界面效应, 以及特殊的三维 空心结构, 红毛丹状磷化钴@锄钴氧空心微米小球表现出优异的析氢催化性能和稳定性.

关键词: 磷化钴@钿钴氧; 红毛丹状; 空心微米小球; 界面效应; 析氢反应

收稿日期: 2019-09-14. 接受日期: 2019-10-18. 出版日期: 2020-04-05.

*通讯联系人. 电话: (020)84110085; 电子信箱: ligaoren@mail.sysu.edu.cn

\#通讯联系人. 电子信箱: ceswmm@mail.sysu.edu.cn

本文的电子版全文由Elsevier出版社在ScienceDirect上出版(http://www.sciencedirect.com/science/journal/18722067). 